\title{
Assessment of agricultural land loss due to mining in Moscow region
}

\author{
Ksenia Naumova*, Elena Stanis, Elena Latushkina, and Nikolai Buldovich \\ Peoples Friendship University of Russia (RUDN University), Faculty of Ecology, 6 Miklukho- \\ Maklaya Street, Moscow, 117198, Russian Federation
}

\begin{abstract}
The study discusses the impact of open cuts for the extraction of common minerals on soil resources and agricultural lands in Moscow region (MR). For this, the features of soil cover in Moscow region and the distribution of soil types by their use as agricultural resources were analyzed. Further, it was determined which types of soils are subject to varying degrees of open cut load. As a result, a schematic map of the soil cover with open cut load zones was made. It is shown which agricultural lands exposed to open cuts of varying intensity. A conclusion is made about the types of soil cover, which accounts for the greatest and least open cut load, as well as the degree of impact of open cuts on agricultural land resources and the correlation between the degree of open cut load and type of agricultural land use. It is shown that the most fertile soils, which occupy only $2.9 \%$ of the MR area, are not affected by the open cut load at all. The greatest open cut load is associated with agricultural lands, represented mainly by various sod-podzolic soils, which occupy $70.5 \%$ of the territory of the Moscow region. If economic trends and population growth rates in the Moscow region continue until 2030, we should expect a further increase in the influence of open cut load on agricultural land towards its intensification.
\end{abstract}

\section{Introduction}

The aim of the study is to identify the effects of open cut mining development on land resources, primarily on agricultural land in the Moscow region (MR) which is the most developed economic region with a high demographic load. Since economic progress and increase in population leads to the need of extraction of minerals, first of all commonly occurring mineral resources, with open cut mining. Therefore, there is an interdependence of the open cut mining development with the economic progress and population growth. The relevance of the study may lie in identifying such a trend, which can allow predicting the further impact of open cut mining on agricultural land resources.

The largest number of open cuts in Moscow Region are developing commonly occurring mineral resources, which are an important component of Moscow Region resource potential. Common mineral resources are a raw material base for road construction, production of building materials, etc. Due to the constantly growing

\footnotetext{
* Corresponding author: shunenkova-ko@rudn.ru
} 
population flow, the needs of construction complex for raw materials are increasing. In the old-developed regions, to which the MR belongs, there is an uncontrolled depletion of minerals, the irrational extraction of which leads to a negative impact not only on the environment, but also on the living conditions and population health in areas of intensive open cut mining. [1]

In the Moscow region, almost all deposits are developed with open cut mining. The process of withdrawing resources is accompanied by an aggressive invasion to environment and disruption of natural balance. Therefore, it becomes necessary to occupy more and more land areas for the placement of overburden, enrichment waste, and sludge.

The prevalence of slope surfaces $\left(12^{\circ}-30^{\circ}\right)$ and permeable displaced overburden in open cut complexes contributes to the processes of gravity sorting, landslide movement of material, suffusion and other negative exogenous processes [2-4]. The depth of open cuts is usually 15-20 m, in some cases up to $100 \mathrm{~m}$ [5].

In addition, not only the open cuts themselves, but also their infrastructure, have a negative impact on the ecological situation of the territory: the soil cover is destroyed and disturbed, vegetation is depressed and destroyed too.

\section{Methods and materials}

As a source of information for assessing the open cut load on the territory of MR, data from official sources were used: the register of primary and interpreted information of the Unified Geological Information Fund about the subsoil, the State Cadastre of deposits and occurrences of minerals, information reports of the Ministry of Natural Resources in MR. The State Register of Reserves of MR contains about 720 deposits of common minerals with total reserves of industrial categories of more than 2 billion $\mathrm{m}^{3}$ [6].

Deposits of common minerals were selected from the consolidated state register of subsoil plots of the Unified Geological Information Fund.

Mineral resources of the Moscow region include deposits of 18 types of minerals, which are dominated by building sands and sand\&gravel rocks, the total reserves of which are 1 billion 296 million $\mathrm{m}^{3}$ (51.4\% of the total reserves) and peat with balance reserves of 728,3 million $\mathrm{m}^{3}(29.0 \%)$ then, in descending order: brick raw materials - 180.0 million $\mathrm{m}^{3}$ (7.2\%), carbonate rocks - 177.0 million $\mathrm{m}^{3}(7.0 \%)$, expanded clay and thermolite raw materials - 72.7 million $\mathrm{m}^{3}(2.9 \%)$, refractory clays - 58.0 million $\mathrm{m}^{3}(2.3 \%)$ [6]. The percentage of minerals extracted in Moscow Region is shown in Fig. 2.

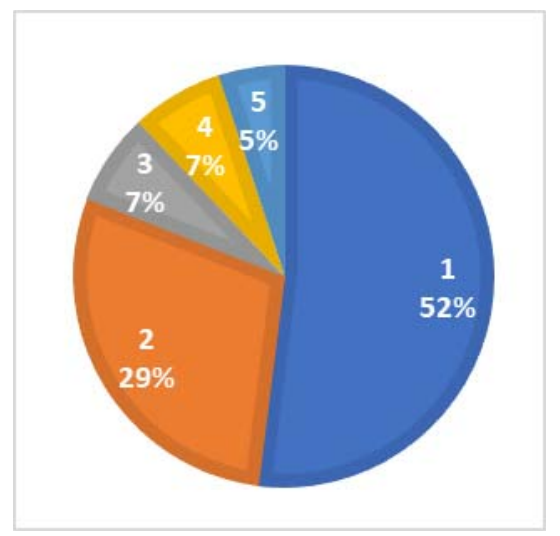

Fig. 1. The structure of the mineral resource base of common minerals: (1) sand\&gravel rocks $-52 \%$, (2) peat $-29 \%$, (3) brick raw materials $-7 \%$, (4) carbonate rocks $-7 \%$; (5) others: expanded clay and thermolite raw materials $(2.9 \%)$, refractory clays $(2.3 \%)[6]$. 
The Moscow region is located in 2 natural areas - the central southern taiga zone and the central forest-steppe zone, on which genetically different soils from podzols to chernozems soils were formed, which make up its agricultural land resources. Sod-podzols occupy $70.5 \%$ of the MR; gray forest soils - $19.0 \%$; floodplain soils - 6.4 ; chernozems $2.9 \%$; peat-bog soils - $0.8 \%$; soddy soils - $0.4 \%$ (Fig. 2 ).

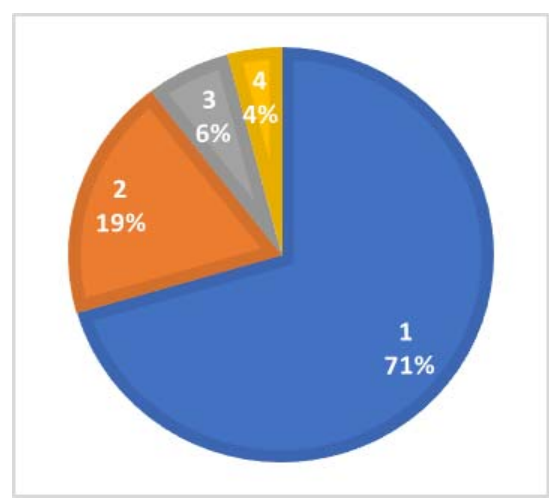

Fig. 2. Distribution of soils in Moscow region, \%: (1) sod-podzols - 70.5\%; (2) gray forest soils $19.0 \%$; (3) floodplain soils -6.4 ; (4) others (chernozems, peat-bog soils, soddy soils) $-4,1 \%$

According to data of the Soil Science Institute of Russian Academy of Agricultural Sciences, we have compiled a schematic map of the open cut distribution in Moscow region on various types of soils. It is shown in Fig. 3.

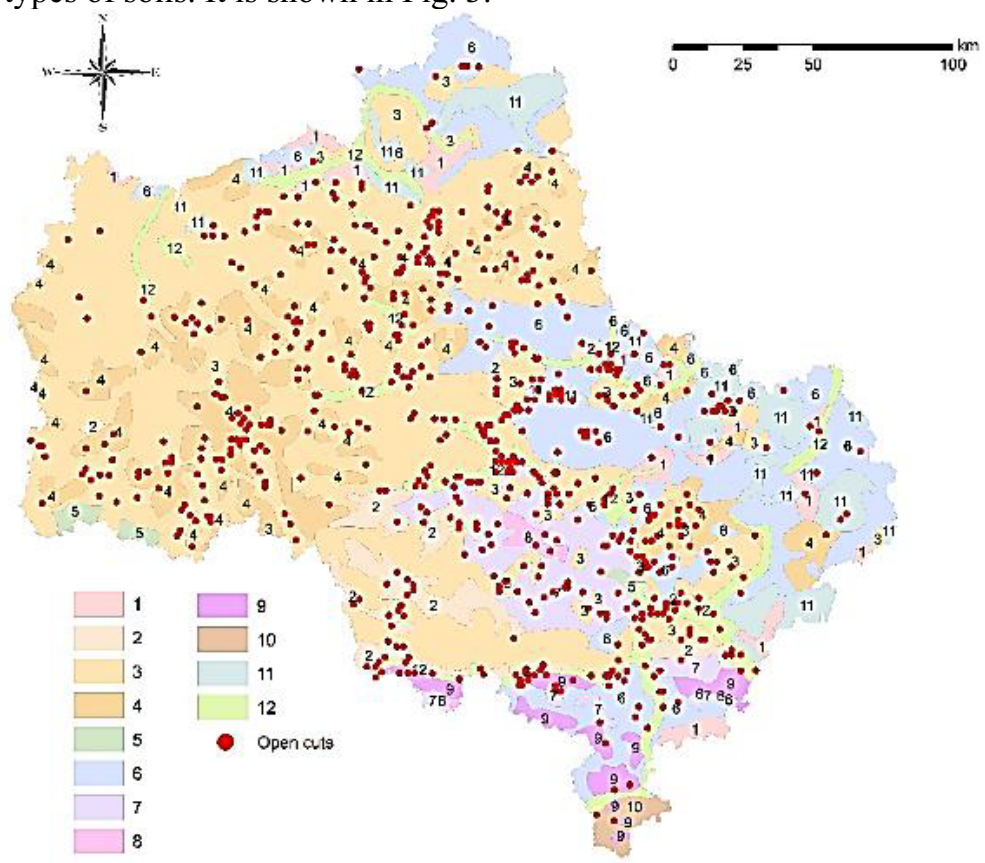

Fig. 3. Soil schematic map of Moscow region with open cut distribution. Legend: 1 - podzolic and podzols; 2 - soddy-slightly podzolic; 3 - soddy-medium podzolic; 4 - sod-strongly podzolic; 5 - sodgley; 6 - bog-podzolic; 7 - light gray forest; 8 - gray forest; 9 - dark gray forest; 10 - leached and podzolized chernozems; 11 - boggy; 12 - alluvial; 13 - open cuts.

The maps were made with ArcGis geographic information system, which uses the following satellite data: Landsat, MODIS, and highly detailed satellite imagery. 
In soil texture, light and medium loamy soils prevail $-67.7 \%$; sandy and sandy loam $16.2 \%$; heavy loamy and clayey - $16.1 \%$. In accordance with soil-geographic zoning system, the main part of Moscow region is located in the subzone of southern taiga sodpodzolic soils (Central Russian province of sod-podzolic medium-humus soils), and only small parts of the region are in the zone of gray forest soils of broad-leaved forests (Central Russian province of gray forest soils) and in the zone of podzolic, leached and typical chernozems and gray forest soils of the forest-steppe.

In the current research we used the materials of our previous study [7] where the following assumption was made. As there are 720 open cuts in Moscow region and total are of Moscow region is $44,300 \mathrm{~km}^{2}$, on average there is one sand and sand \& gravel open cut per $61,4 \mathrm{~km}^{2}$. The largest number of open cuts unit square was 19 , and the smallest -1 . On a part of the territory, there are no open cuts in unit squares (96 with a total area of 21,600 $\mathrm{km}^{2}$ ). There a visual density model was made according to the following consumption: no open cut load - 0 open cut, light load - 1-5 open cuts, average load - 6-10 open cuts, high load - 11-15 open cuts. The schematic map of open cut load from the previous research [7] was used in the current research to show the correlation between mining and agricultural industry.

\section{Results and discussion}

Using the map of the density and intensity of open cut in the Moscow region that we previously made and soil schematic map (Fig. 3), we can assess the agricultural land loss due to mining in Moscow Region [7]. As a result, a schematic map of the open cut load density on the soils of Moscow region was made (Fig.4).

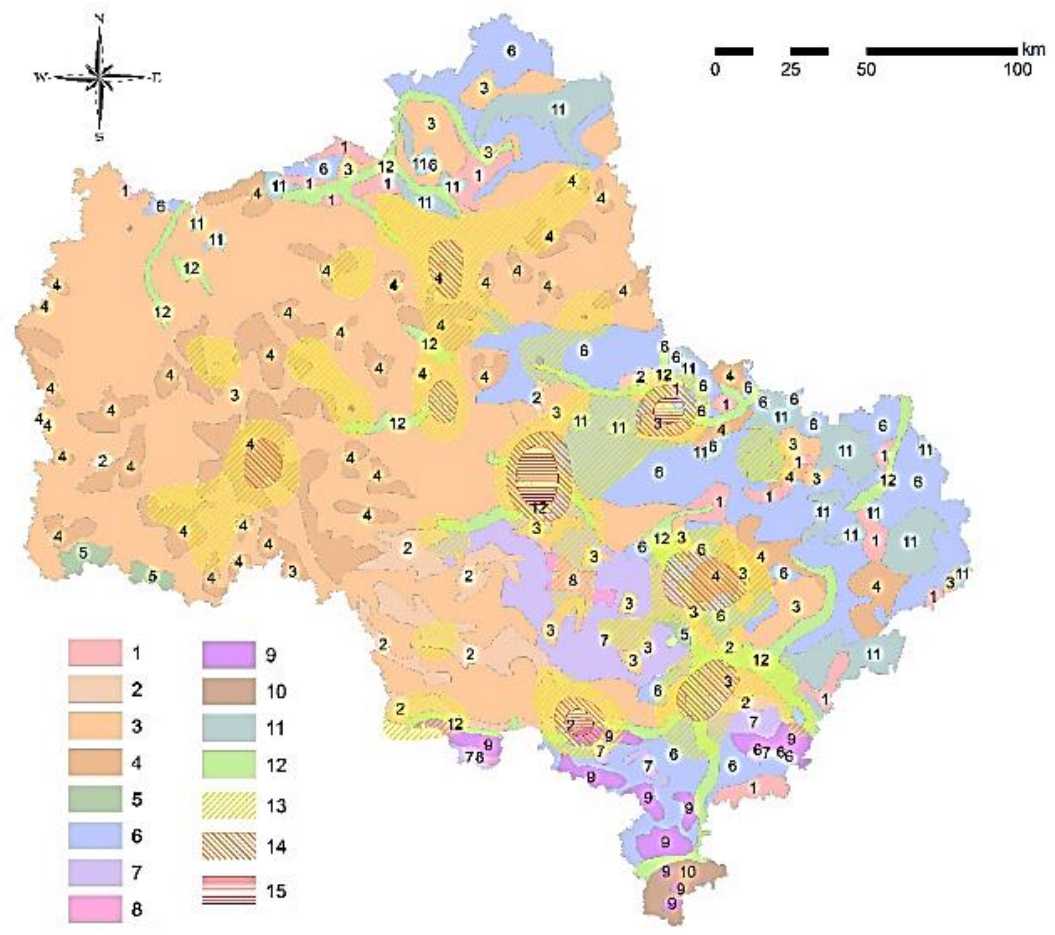

Fig. 4. Soil map of Moscow region with open cut load zones. Legend: soils 1-12 in accordance with Fig. 3. Open cut load zones: 13 - moderate load; 14 - increased load; 15 - high load. 
In Fig. 4 we can see that the greatest load is associated with the areas of soddy soils, mostly to medium and strongly podzolic soils. Areas of moderate career load also affect podzolic soils, forest, and alluvial soils. The most fertile chernozems in Moscow region do not have an open cut load. More than half of the area occupied by forest soils, which is associated with a moderate career load, is used in agriculture.

The soils of the region have a rather low natural fertility, unsatisfactory agrophysical properties, low buffering capacity due to the unsatisfactory composition of soil humus (the predominance of fulvic acids over humic acids) and are unable to withstand negative external influences, primarily erosion. More than $15 \%$ of all agricultural land, incl. almost $18 \%$ of arable land is subject to erosion. Therefore, the additional technogenic load on the soils only worsens their condition.

The most agriculturally developed soils are chernozems. Their agricultural use (excluding household lands) reaches $70.7 \%$. But they play a minimal role in the soil and agricultural resources of the region. In second place in terms of use there are gray forest soils, $64.3 \%$ of which is under agricultural land. They also occupy $19 \%$ of the resource potential. The zone of sod-podzolic soils is more forested and less agriculturally used than the forest-steppe zone. Small tracts of soddy-calcareous and soddy-gley soils (46.6\%), as well as bog-podzolic (sod-podzolic, gley and peat-podzolic gley) soils (45.2\%) are most agriculturally developed in it. Among the bog-podzolic soils, the most developed are soils of heavy texture, $98.2 \%$ of which is used for agricultural land. Low productive swampy forests on loam have been turned into hayfields (36.9\%) and pastures (34.1\%). Arable land occupies about $27.9 \%$ of these soils. Boggy-podzolic sandy loam soils (26.8) are less developed in agricultural terms and sandy soils (11\%) are much less developed. Arable land here plays an equal or predominant role with fodder lands. A significant part of agricultural land on bog-podzolic soils is drained (about 37.2 thousand hectares or $4.1 \%$ ), while on loamy soils, both arable land and hayfields and pastures are drained, and on sandy loam soils - mainly arable land. Swamp-podzolic soils are partially irrigated because of their development for vegetable crops.

\section{Conclusions}

Thus, we revealed that the low and medium open cut impact on land and agricultural resources mainly corresponds to soddy-strongly podzolic and soddy-medium podzolic soils, which are located in the southeastern and northwestern parts of Moscow region.

A high open cut impact on agricultural land resources corresponds to soddy-mediumpodzolic soils, partly on soddy-slightly podzolic and podzolic soils. The territories are associated with the following industrially developed districts: Lyubertsy district (population density 2526 people), Pavlovo-Posad district (population density - 150 people), partly with Ramensky district (population density - 210 people) and Kashirsky district, with a rather high urban population density.

These territories have a clearly conspicuous zoning: in the center the load is high, then towards the outskirts it turns into medium, and then into weak. A similar zoning is observed for areas with an average open cut load. On the positive side, the most valuable agricultural resource potential, represented by chernozems, is not affected by any open cut load.

In the future, we should expect, with positive dynamics of economic development, population growth, and, accordingly, various types of construction activities, an increase in the areas of open cut load on agricultural land and a decrease in agricultural land resource potential. 


\section{References}

1. N.V. Nazarenko, Materials of the IV Intern. scientific. conf., 11-14, (2010)

2. A.A. Kozyrev, S.A. Panichkin, E.V. Kasparyan, V.V. Rybin, A.N., Miner's Week 2002, 2, 16-25, (2002)

3. A.G. Kornilov, A.N. Petin, E.V. Kichigin, Yu.A. Prisny, A.F. Kolchanov, A.V. Prisny, Izvestiya RAS, 2 (2008)

4. A.I. Perelman, A.E. Vorobiev, Vestnik MSU, 5, 16-22, (1995)

5. Yu. Yu. Alekseeva, I.V. Buzyakova, Geology, Geography and Global Energy, 2, 139148, (2020)

6. On the state of natural resources and the environment of the MR in 2018: information release. (Publishing house of the Ministry of ecology and nature management of the MR, Moscow, 2019)

7. E.V. Stanis, K.O. Naumova, CAJG 2020, (to be published) 